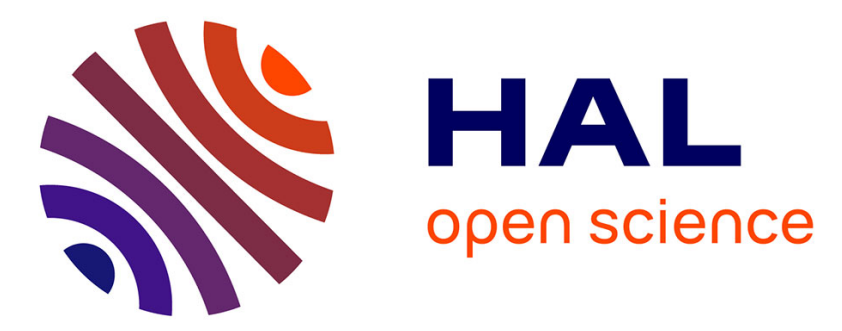

\title{
Relationship Between Variants and Inventory Under Consideration of the Replenishment Time
}

\author{
Christoph Roser, Hauke Meier, Masaru Nakano
}

\section{To cite this version:}

Christoph Roser, Hauke Meier, Masaru Nakano. Relationship Between Variants and Inventory Under Consideration of the Replenishment Time. IFIP International Conference on Advances in Production Management Systems (APMS), Sep 2017, Hamburg, Germany. pp.382-389, 10.1007/978-3-319-669267_44. hal-01707259

\author{
HAL Id: hal-01707259 \\ https://hal.inria.fr/hal-01707259
}

Submitted on 12 Feb 2018

HAL is a multi-disciplinary open access archive for the deposit and dissemination of scientific research documents, whether they are published or not. The documents may come from teaching and research institutions in France or abroad, or from public or private research centers.
L'archive ouverte pluridisciplinaire HAL, est destinée au dépôt et à la diffusion de documents scientifiques de niveau recherche, publiés ou non, émanant des établissements d'enseignement et de recherche français ou étrangers, des laboratoires publics ou privés. 


\title{
Relationship between Variants and Inventory Under Consideration of the Replenishment Time
}

\author{
Christoph Roser ${ }^{1}$, Hauke Meier ${ }^{2}$, Masaru Nakano ${ }^{3}$ \\ ${ }^{1}$ Karlsruhe University of Applied Sciences, Karlsruhe, Germany \\ (Corresponding Author) \\ christoph.roser@hochschule-karlsruhe.de \\ ${ }^{2}$ Dr. Ing. h.c. F. Porsche AG, Porscheplatz 1, 70435 Stuttgart-Zuffenhausen, Germany \\ ${ }^{3}$ Graduate School of System Design and Management, Keio University, Yokohama, Japan
}

\begin{abstract}
It is common wisdom that the finished goods inventory increases with the number of variants stored in that inventory. However, to the best of our knowledge, this has never been verified. This paper presents research where this relationship has been analyzed both by applying theory and through analytical simulation. The result shows that this common wisdom is not always true. The number of kanban increases as the customer takt decreases if the customer takt is smaller than the replenishment time. If the customer takt is larger than the replenishment time, a change in the customer takt will not change the required minimum inventory of one. Similar holds true for the number of variants.
\end{abstract}

Keywords: finished goods inventory, customer takt, replenishment time, variant reduction

\section{Introduction}

In many companies, the idea of inventory reduction and hence reduction of the associated costs is well received [1], [2], [3]. Unfortunately, the implementation is often lacking [4], [5]. In particular, inventory reduction is often a simple reduction of the target inventory, without the understanding of the underlying relationships. Hence, the relationship of inventory to production has been studied intensively, for example [6], [7], [8]. This paper aims to dig deeper into this relationship, especially the relationship between customer takt and inventory, as well as the related relationship of the number of variants and the inventory.

\section{Relevant Concepts}

To understand the following theoretical and practical analysis, a few concepts from lean manufacturing have to be described briefly. 


\subsection{Customer Takt}

The customer takt (or takt time) is one of the fundamentals for determining the speed of a production system. It represents the average demand of the customer during a time period. To calculate it, you divide the available working time by the customer demand during that time, as shown in equation (1) [9]:

$$
T T=\frac{A T}{C D}
$$

where TT is the customer takt, AT is the available work time, and CD is the total customer demand across all product variants. The calculation hence results in the average time between a customer demand, and therefore is also the target speed a system must achieve to satisfy this demand in the long term. The customer takt can be calculated for the total of all products, as well as for an individual product variant.

\subsection{Kanban-based Pull System}

The analyzed system is based on a pull system using a kanban-based pull system. This is a common approach in lean manufacturing [10]. Pull production has many advantages over conventional push production, most significantly a consistent and stable management of inventory, requiring less inventory than a push system and hence avoiding the associated costs (see above) [11].

\subsection{Replenishment Time}

The replenishment time is the time needed to replenish a part. This does not mean when the next part comes down the line, but instead how long it takes for a work order to come back with a part. Fig. 1 illustrates this, for an example, with three processes.

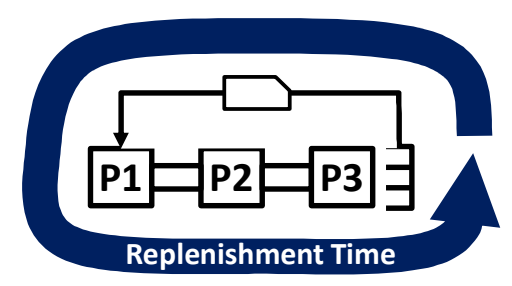

Fig. 1 Illustration of replenishment time using value stream mapping notation. Source: Author

\section{Theoretical Approach}

First we start with a theoretical approach. For simplification we assume that our system has no variation or fluctuation. This of course is a widely optimistic assumption for practical use. However, it is useful to determine the theoretical best-case scenario. We also assume that there is only one finished good inventory from which the 
customer demand is satisfied. Multiple inventories for different customer groups would of course increase the total inventory.

\subsection{Customer Takt Larger than Replenishment Time}

Assume the system produces one product and the customer takt is significantly larger than the replenishment time. In order to be able to deliver to the customer without delay, we need to have at least one of these products in stock. If the customer wants a product, he receives the single piece in stock, and then we reproduce it to increase stock again to one piece. Hence, the behavior of the inventory over time may look like Fig. 2. Overall, we require only a single kanban card to manage production. Hence we have at most an inventory of one.

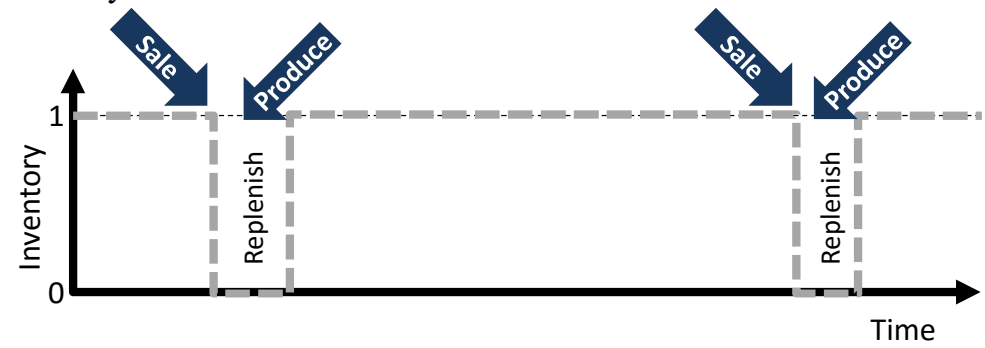

Fig. 2 Theoretical behavior if customer takt is significantly larger than the replenishment time. Source: Author

\subsection{Customer Takt Smaller than Replenishment Time}

In a second theoretical example, we assume that the customer takt is smaller than the replenishment time. In other words, the customer orders faster than the time it takes to reproduce one part. This is easily resolved by adding multiple kanban to the system. The number of kanban needed is shown in equation (2), where $\mathrm{K}$ is the number of kanban.

$$
K=\operatorname{Round} U p\left[\frac{R T}{T T}\right]
$$

Please note that this formula is valid regardless of the relationship of replenishment time and customer takt, but is still assuming no fluctuations. If the customer takt is much larger than the replenishment time as in the previous theoretical assumption, we need only a single kanban as shown in 3.1.

\subsection{Kanban and Inventory over Customer Takt}

Now it is possible to calculate the number of kanban for any customer takt. Please note again that the assumed lack of fluctuations prevents the use of these simple 
equations for practical applications, but it is to serve a best-case illustration. The resulting general behavior is shown in Fig. 3. The time where the customer takt equals the replenishment time is indicated with a vertical gray line.

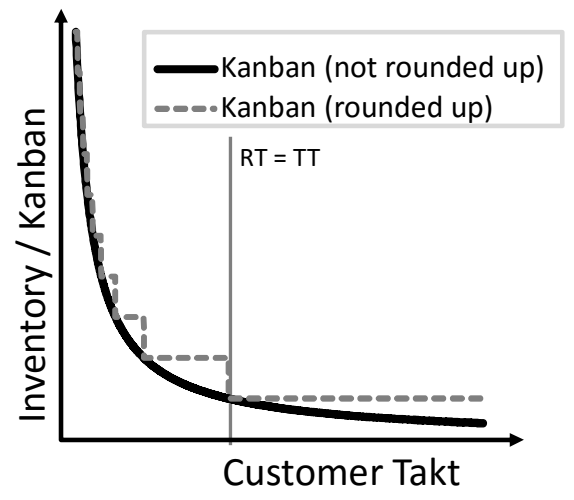

Fig. 3 Behavior of the number of kanban and inventory in relationship to the customer takt. Units are intentionally missing, as this is a thought experiment. Source: Author

\subsection{Kanban and Inventory over Variants}

Using the previous equations, it is also possible to make a theoretical model of the kanban in relationship to the number of variants. In industry, additional variants are introduced with the hope of selling more products overall, although the actual outcomes vary. To allow easier comparison of different number of variants, we assume that the total quantity of products sold remains constant. In a second simplification, we assume that the total quantity produced is always split evenly across all available variants. Naturally, in industry applications this is rarely the case. Yet, this assumption allows for easy comparison of different production quantities with different variants. Similar results should hold true also if the quantity for the different variants vary. As we will see later, it all depends on whether the customer takt for a variant is faster or slower than the replenishment time. The customer demand for one variant $C D_{i}$ is as follows:

$$
C D_{i}=\frac{C D}{n} \text { for all } i \in(1, n)
$$

Substituting gives us the equation for the takt time and the number of kanban for product $i$.

$$
\begin{array}{r}
T T_{i}=\frac{A T \cdot n}{C D} \text { for all } i \in(1, n) \\
K_{i}=\text { Round } U p\left[\frac{R T \cdot C D}{A T \cdot n}\right]
\end{array}
$$

From this we can easily calculate for all variants $n$ of the total number of kanban $\mathrm{K}$ as shown in (6) and (7), which are the same equations with different substitutions. 


$$
\begin{gathered}
K=n \cdot K_{i} \\
K=n \cdot \operatorname{Round} U p\left[\frac{R T}{T T \cdot n}\right]
\end{gathered}
$$

Fig. 4 shows the results for keeping the total customer demand constant and varying only the number of variants. Again, please note that this is an idealized case with no fluctuation.

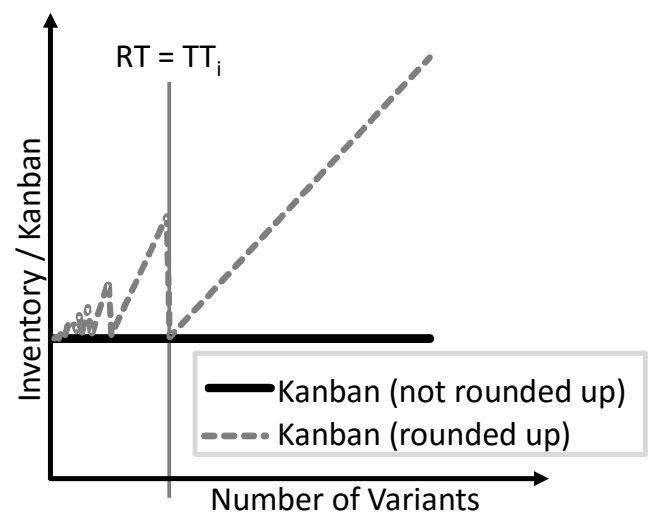

Fig. 4 Behavior of the number of kanban and inventory in relationship to the number of variants. Units are intentionally missing, as this is a thought experiment. Source: Author

The time where the customer takt derived from the number of variants equals the replenishment time is indicated with a vertical gray line. Of interest again is the number of kanban that are not rounded up. If the number of variants is below the threshold where the customer takt equals the replenishment time, then the total number of kanban (not rounded up) does not change regardless of the number of variants.

On the right of the threshold, the minimum number of kanban cards increases with the number of variants. Hence, while the right side supports the initial theory that the inventory increases with the number of variants, the model to the left of the threshold does not hold true to this theory. We will discuss this highly interesting result later in the conclusions. However, these theoretical results have the limiting assumption of no fluctuations or variations in the customer takt and replenishment time. Before we analyze these interesting results in more detail, we will investigate the same questions using an experimental approach.

\section{Experimental Approach}

To test these results analytically, we used a commercially available simulation tool Simul8. This analysis was conducted as part of a master thesis by one of the authors [12]. Please refer to [12] for details on the simulation set up. 


\subsection{Kanban and Inventory over Customer Takt}

Fig. 5 shows the resulting experimental relationship between the inventory and the customer takt. For clarity we also added the theoretical model with the not-roundedup number of kanban. Please note that due to the large numbers involved, both axes of Fig. 5 are on a logarithmic scale, resulting in straight lines rather than the curves seen in Fig. 3. The data is shown for different delivery performances, representing the percentage of customer demands that could be fulfilled immediately. The actual replenishment time of the simulation is also added as a dotted line where the replenishment time equals the customer takt.

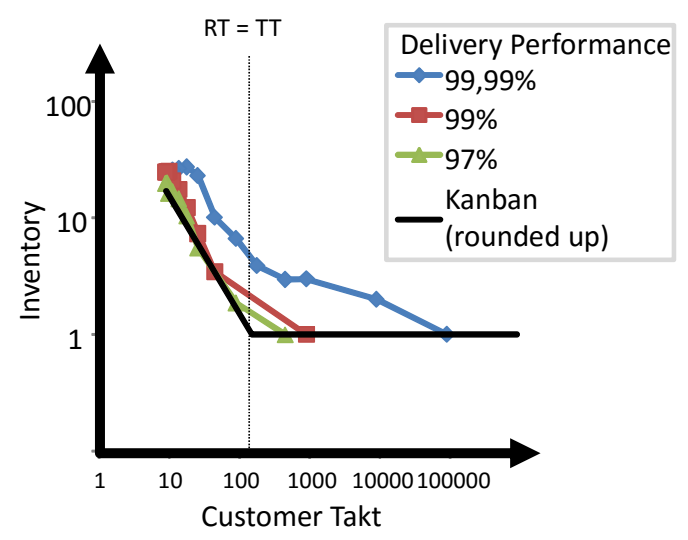

Fig. 5 Simulated behavior of the inventory in relationship to the customer takt. Source: Author

\subsection{Kanban and Inventory over Variants}

Fig. 6 shows the resulting experimental relationship between the inventory and the number of variants. For clarity we also added the theoretical model with the notrounded-up number of kanban. Please note that again due to the large numbers involved, both axes of Fig. 6 are on a logarithmic scale. Again, the actual replenishment time of the simulation is also added as a dotted line where the replenishment time equals the customer takt for a given number of variants. 


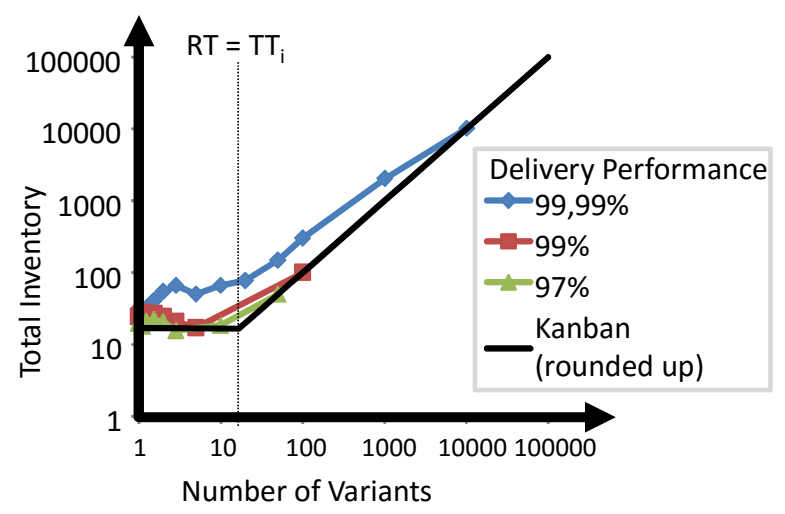

Fig. 6 Simulated behavior of the inventory in relationship to the number of variants. Source: Author

Overall, the simulated results overlap very nicely with the theoretical assumptions, therefore verifying the theoretical model. The full data is available through [12].

\section{Conclusions}

Our research shows that the number of kanban increases as the customer takt decreases as long as the takt is smaller than the replenishment time as shown in Fig. 5 and Fig. 3. Surprisingly, however, if the customer takt is larger than the replenishment time, it has no influence on the total number of kanban and the inventory.

The situation becomes even more interesting for the number of variants as shown in Fig. 6 and Fig. 4. On the right-hand side, you get the results expected by common wisdom on the shop floor. Your inventory increases as the number of variants increases. The most interesting result of this analysis, however, is on the left side. The inventory remains constant in theory and nearly so in practice. This means that as long as both the old and the new variants have a customer takt smaller than the replenishment time, you can add additional variants without incurring the penalty of additional inventory. The common wisdom on the shop floor is not true as long as you sell enough products.

\section{References}

[1] C. Hofer, C. Eroglu, and A. Rossiter Hofer, "The effect of lean production on financial performance: The mediating role of inventory leanness," Int. J. Prod. Econ., vol. 138, no. 2, pp. 242-253, Aug. 2012.

[2] C. Eroglu and C. Hofer, "Lean, leaner, too lean? The inventory-performance link revisited," J. Oper. Manag., vol. 29, no. 4, pp. 356-369, May 2011. 
[3] K. Demeter and Z. Matyusz, "The impact of lean practices on inventory turnover," Int. J. Prod. Econ., vol. 133, no. 1, pp. 154-163, Sep. 2011.

[4] L. Richter, "Cargo Cult Lean," Hum. Resour. Manag. Ergon., vol. 5, no. 2, pp. 84-93, 2011.

[5] J. P. Ignizio, Optimizing Factory Performance: Cost-Effective Ways to Achieve Significant and Sustainable Improvement (Kindle Edition), 1st ed. New York: Mcgraw-Hill Professional, 2009.

[6] E. Akçalı and S. Çetinkaya, "Quantitative models for inventory and production planning in closed-loop supply chains," Int. J. Prod. Res., vol. 49, no. 8, pp. 2373-2407, Apr. 2011.

[7] J. Venkateswaran and Y.-J. Son, "Effect of information update frequency on the stability of production-inventory control systems," Int. J. Prod. Econ., vol. 106, no. 1, pp. 171-190, Mar. 2007.

[8] E. Aggelogiannaki, P. Doganis, and H. Sarimveis, "An adaptive model predictive control configuration for production-inventory systems," Int. J. Prod. Econ., vol. 114, no. 1, pp. 165-178, Jul. 2008.

[9] A. B. Badiru and O. A. Omitaomu, Handbook of Industrial Engineering Equations, Formulas, and Calculations, New. edition. Boca Raton, FL: Industrial Innovation, 2010

[10] Y. Sugimori, K. Kusunoki, F. Cho, and S. Uchikawa, "Toyota production system and Kanban system Materialization of just-in-time and respect-for-human system," Int. J. Prod. Res., vol. 15, no. 6, pp. 553-564, Jan. 1977.

[11] L. C. Lee, "A Comparative Study of the Push and Pull Production Systems," Int. J. Oper. Prod. Manag., vol. 9, no. 4, pp. 5-18, 1989.

[12] H. Meier, "Analyse des Zusammenhangs zwischen Variantenvielfalt, Lagerbeständen und Lieferbereitschaft," Master Thesis, Karlsruhe University of Applied Science, Karlsruhe, Germany, 2016. 